\title{
Vernix Caseosa
}

National Cancer Institute

\section{Source}

National Cancer Institute. Vernix Caseosa. NCI Thesaurus. Code C34328.

A white cheese-like protective material that covers the skin of a fetus. 